\title{
Differences in Turnover Intentions of Nurse Practitioners by Practice Area in the United States
}

\author{
Christine Brown Mahoney \\ Minnesota State University Mankato \\ Paul L. Schumann \\ Minnesota State University Mankato \\ Marilyn L. Fox \\ Minnesota State University Mankato
}

The purpose of this research is to understand the determinants of Nurse Practitioner (NP) turnover intentions. NPs are advanced Registered Nurses. Data on 7,944 NPs were analyzed in four different practice settings. Thirteen job dissatisfaction questions were factor analyzed to create four job dissatisfaction variables, which were then included in a logistic regression of turnover intentions. Results showed that higher NP turnover intentions were associated with higher levels of dissatisfaction with organizational administration, professional treatment, patient workload, and pay and benefits. NP turnover can be reduced, and thereby control costs while improving care, by reducing the four sources of dissatisfaction.

\section{INTRODUCTION AND LITERATURE}

Nurse Practitioners (NPs) are highly skilled advanced Registered Nurses (RNs) who are educated and trained to provide health promotion and maintenance through the diagnosis and treatment of acute illness and chronic conditions; many NPs are also qualified to treat certain medical conditions without the direct supervision of a doctor. The National Sample Survey of Nurse Practitioners (NSSNP) data used for this study finds that about 94 percent of the total NP workforce held a graduate degree and 96 percent had formal certification from a national certifying organization (U.S. Department of Health and Human Services, 2014b). NPs play a critical role in providing medical care, particularly when healthcare providers are attempting to control costs. Turnover of NPs is expensive to the employer, to the patients, and to third-party payers such as insurance companies, which threatens the cost, accessibility, and quality of medical care.

Employers incur turnover costs from recruiting, selecting, and training replacements for NPs who quit. In addition, turnover can result in employee shortages, forcing those remaining employees to have increased workloads. Research has shown increased workloads due to turnover cause burnout, which in turn results in decreased productivity, lesser quality of patient care, and decreased productivity of new hires (Jones, 2004; Jones, 2005; O'Brien-Pallas et al., 2006). Therefore, understanding the determinants 
of turnover of NPs is important if employers are to undertake making changes to the workplace and to the treatment of NPs to reduce turnover, reduce costs, and improve the quality of medical care that patients receive. These costs affect far more than just the organization experiencing higher than desired turnover because the increased costs will be passed on to patients, to payers for healthcare (both private third party and government), and to society.

In the United States (US), recent research has estimated that the average cost of replacing a RN is $\$ 62,000$ to $\$ 67,000$ (Kurnat-Thoma, Ganger, Peterson, \& Channell, 2017), which is approximately equal to the median starting salary of $\$ 68,450$ per year for RNs (Bureau of Labor Statistics, 2016). Since NPs are advanced RNs with additional training and skills, NPs median salary is higher than that of RNs - the average salary of NPs in the US was $\$ 88,200$ (Bureau of Labor Statistics, 2016; Kurnat-Thoma et al., 2017 ) - so the cost of replacing NPs would be higher than that for replacing RNs.

Studies of turnover typically examine turnover intentions instead of actual employee turnover because actual turnover is predicted by turnover intentions (Mobley, Horner, \& Hollingsworth, 1978). Turnover intention is defined as "the last in a sequence of withdrawal cognitions, a set to which thinking of quitting and intent to search for alternative employment also belong" (Tett \& Meyer, 1993: 262). Thus, examining turnover intentions allows managers to understand what actions they can take to influence employees before the employees actually quit.

Job satisfaction, defined by Locke (1969: 316) as "the pleasurable emotional state resulting from the appraisal of one's job as achieving or facilitating the achievement of one's job values," is a primary determinant of turnover intentions in the literature. The research literature finds that nurse job satisfaction is associated with job characteristics such as nurse participation in hospital affairs, nurse-physician relations, and patient workload (Aiken et al., 2011; Nantsupawat et al., 2011). Research concludes that job characteristics are more important in predicting job satisfaction than individual nurse demographic characteristics (Adams \& Bond; 2000).

NPs typically work in one of four different practice settings that are classified in the 2012 NSSNP (Health Resources and Services Administration, 2012): Primary Care Specialties (e.g., family practice, internal medicine, geriatrics), Internal Medicine Subspecialties (e.g., cardiology, endocrinology, gastroenterology, oncology), Surgical Specialties (e.g., general surgery, orthopedics), or Other (e.g., allergy and immunology, dermatology, emergency care, hospitalist, intensive care). The job characteristics experienced by an NP may differ by their practice setting. For example, NPs in the Internal Medicine Subspecialties typically have additional specialized knowledge of their subspecialty. For another example, NPs in the Surgical Specialties are typically dealing with patients who are sicker and undergoing surgery; surgical NPs are also more likely to deal with patients who are noncommunicative (e.g., due to anesthesiology).

Since job characteristics are important determinants of job satisfaction, and since job satisfaction is an important determinant of turnover intentions, the relationship between job satisfaction and turnover intentions may differ by practice setting. Poghosyan, Liu, Shang, and D'Aunno (2017, p. 168) found that “... NPs practicing in primary care organizations with favorable practice environments, including better working relations with physicians and administration, better support for NP independent practice, and clear role visibility, are more likely to be satisfied with their jobs and less likely to report intent to leave."

The aim of this study is to examine the differences in determinants of turnover intention between practice settings for NPs. Previous studies have not looked at different practice settings for NPs and how that affects turnover intentions. The practical implications are important as they can more specifically inform meaningful management interventions in organizations struggling to develop and maintain sufficient employee expertise to sustain the quality of patient care while managing costs. Our study builds on previous work that addresses the determinants of turnover intention of NPs using the 2012 National Sample Survey of Nurse Practitioners (Health Resources and Services Administration, 2012). 


\section{METHODS}

The dataset we analyzed was the 2012 National Sample Survey of Nurse Practitioners (Health Resources and Services Administration, 2012). It is a national stratified random sample of NPs; it included information on licensure, education, clinical practice characteristics, and demographics. The study was conducted by the Health Resources and Services Administration (HRSA), and resulted in a representative sample by using listings of all actively licensed NPs from each state licensing board, weighted proportionally by the size of the state. This resulted in a total of 12,923 surveys completed by NPs, with a response rate of $60.1 \%$. More information, and the data itself, can be found at HRSA (2012). After omitting NPs who did not have the necessary data, the sample we analyzed consisted of a total of 7,944 NPs: 3,843 working in primary care, 1,345 in internal medicine subspecialties, 724 in surgical positions, and 2,032 in other.

The dataset included 13 questions that measured dissatisfaction with various aspects of work that might be associated with turnover intentions. Correlation analysis revealed high correlations among the 13 dissatisfaction variables. The high correlations among the 13 variables would make including all of them in a model of turnover intentions problematical because of collinearity, which would result in not being able to accurately separate the effects of each dissatisfaction variable on turnover (Midi et al., 2010). Furthermore, the high correlations suggest that the 13 dissatisfaction variables were not measuring independent constructs, but instead were measuring a smaller number of latent constructs that can be represented by common factors (Guilford, 1954; Lord \& Novick; 1974). As a consequence, we performed a factor analysis of the thirteen dissatisfaction variables. The results of the factor analysis provided a smaller number of latent constructs with improved reliability of measurement (Guilford, 1954; Lord \& Novick, 1974).

Analyses were done using SAS software, Version 9.4 (2017). The factor analysis estimation method was maximum likelihood with varimax rotation. The eigenvalues (characteristic roots) from the correlation matrix of the 13 dissatisfaction variables were examined to see how many latent constructs had eigenvalues larger than one; there were four-i.e., four common factors existed.

The four common factors are shown in Table 1 with the factor names suggested by the variables included in each factor and the dissatisfaction questions (variables) that were included in each factor. These four dissatisfaction factors are subsequently included in logistic regression to identify the significant predictors of turnover intention. The measure of internal consistency or reliability, Cronbach's alpha, are also shown in Table 1. Results of Cronbach's alpha were 0.80 for Patient Workload (F1), 0.81 for Professional Treatment (F2), and 0.81 for Organizational Administration (F3). These are all within the acceptable range for Cronbach's alpha, which, according to Nunally (1978: 245-246), should be 0.70 or higher. Cronbach's alpha could not be computed for the fourth factor because it has only one variable. 
TABLE 1

FACTOR ANALYSIS OF DISSATISFACTION VARIABLES

F1 Dissatisfaction with Patient Workload; Cronbach's a=0.80

Dissatisfaction with the proportion of time in patient care

Dissatisfaction with patient load

Dissatisfaction with patient mix

Dissatisfaction with the amount of paperwork required

Dissatisfaction with the number of hours worked, including overtime

F2 Dissatisfaction with Professional Treatment; Cronbach's a $=0.81$

Dissatisfaction with the sense of value for what you do

Dissatisfaction with respect from physician colleagues

Dissatisfaction with respect from other colleagues

Dissatisfaction with level of autonomy

F3 Dissatisfaction with Organizational Administration; Cronbach's a=0.81

Dissatisfaction with amount of administrative support

Dissatisfaction with opportunities for professional development

Dissatisfaction with input into organizational/practice policies

F4 = Dissatisfaction with Salary and Benefits

Dissatisfaction with the salary/benefits

"Turnover intention" was our dichotomous dependent variable; it equaled 1 if the respondent planned to leave their primary NP position in 2 years or less, and equaled 0 otherwise. We used the logistic regression procedure in SAS to analyze turnover intention in our data because logistic regression is designed for estimating models of the relationship between a dichotomous dependent variable and multiple independent variables (Agresti, 2007; Kutner et al., 2004; Midi et al., 2010; SAS Software, Version 9.4, 2017).

Based on the literature, we hypothesized that turnover intentions would be positively related to each of the four measures of job dissatisfaction that resulted from the factor analysis: dissatisfaction with patient workload, professional treatment, organizational administration, and salary and benefits. In addition to the four dissatisfaction variables from the factor analysis, we included two sets of control variables that might affect turnover intentions: demographic variables and work setting characteristics.

In particular, we included three demographic variables:

1. Marital status: Married $=1$ if married; 0 otherwise. We included this variable because married NPs may be more or less likely to turnover depending on their spouse's job situation.

2. Age: Measured in 5-year categories. We included this variable because younger NPs may be more likely to turnover because they have more years to work and thus recoup the costs of turnover, or less likely to leave because of their youthful optimism regarding their career and workplace situations.

3. Urban: Urban $=1$ if the NP resides in an urban area and $=0$ otherwise. We included this variable because the existence of more abundant job opportunities in urban areas may affect NPs decision to change jobs.

And we included 4 variables that describe characteristics of NPs' work settings: 
1. Physician present $>50 \%$ time: The amount of time a physician is present (if physician is present more than $50 \%$ of the time $=1$; otherwise $=0$ ) because of the potential for conflict between NPs and physicians.

2. Paid hourly: Whether the NPs are paid hourly (paid hourly=1 if the NP is paid hourly, and $=0$ otherwise) because being paid hourly has the possibility of the NP increasing their income by earning overtime pay for extra hours worked; conversely, being paid hourly may indicate that the organization does not consider this a "professional" position.

3. Bill independently: Whether the NPs bill independently (bill independently=1 if the NP bills independently, and $=0$ otherwise) because NPs who bill independently have more control over their earnings.

4. Must accept MD's decision: Whether the NPs work in an environment where they are supervised by a physician and must accept the physician's decisions (must accept $=1$ if the NP is they work in this environment, and $=0$ otherwise) because NPs who work in such an environment may dislike the lack of control they have over their patients' care.

\section{RESULTS}

Table 2 displays the means of the variables in each of the four subsamples. Significant differences exist between many two-way comparisons of the variables presented for the four NP practice settings; we comment only on the statistically significant differences using t-tests. A greater percentage of NPs intend to leave their position in two years or less in Other $(22 \%)$ than in Internal $(18 \%)$ or Surgical (18\%), and a greater percentage in Primary (21\%) than Internal (18\%) and Surgical (18\%). A greater percentage of NPs are married in Internal (75\%) and Primary $(77 \%)$ than in Other $(70 \%)$, and a greater percentage married in Primary $(77 \%)$ than Surgical (71\%). A greater percentage of NPs work with a physician present more than $50 \%$ of the time in Internal $(80 \%)$ and Surgical $(81 \%)$ than Other $(60 \%)$, a greater percentage in Internal $(80 \%)$ than Primary $(60 \%)$, and a greater percentage in Surgical $(81 \%)$ than Primary $(60 \%)$. A smaller percentage of NPs are paid hourly in Internal $(19 \%)$ and Surgical $(21 \%)$ than Other (31\%), a greater percentage in Primary (31\%) than in Internal (19\%), and a greater percentage in Primary (31\%) than in Surgical (21\%). In term of age, those NPs in Internal (4.07) and Surgical (3.86) are slightly younger than in Other (4.24), Primary (4.33) are slightly older than Internal (4.07), and Surgical (3.86) are slightly younger than Internal (4.07) and Primary (4.33). A greater percentage of NPs work in an environment where they are supervised by a physician and must accept the physician's decisions in Other $(8 \%)$ and Internal (9\%) than in Primary (3\%); a greater percentage of NPs work in an environment where they are supervised by a physician and must accept the physician's decisions in Surgical (13\%) than in Other $(8 \%)$, Internal $(9 \%)$, or Primary $(3 \%)$. The distribution of NPs between urban and rural settings, from the least in urban to the most, are Primary (73\%), Other (84\%), Surgical (87\%), and Internal (90\%). 
TABLE 2

DIFFERENCES IN NURSE PRACTITIONER PRACTICE SETTINGS

\begin{tabular}{|l|r|r|r|r|}
\hline Variable & Other & Internal & Primary & Surgical \\
\hline $\mathbf{N}$ & 2,032 & 1,345 & 3,843 & 724 \\
\hline F1 patient workload & -0.06 & -0.03 & -0.02 & -0.11 \\
\hline F2 professional treatment & 0.02 & -0.05 & -0.08 & 0.07 \\
\hline F3 organizational administration & 0.00 & 0.03 & -0.08 & 0.00 \\
\hline F4 salary and benefits & -0.07 & -0.07 & 0.03 & -0.21 \\
\hline Married & 0.70 & 0.75 & 0.77 & 0.71 \\
\hline Physician present $>\mathbf{5 0 \%}$ time & 0.60 & 0.80 & 0.60 & 0.81 \\
\hline Paid hourly & 0.31 & 0.19 & 0.31 & 0.21 \\
\hline Age (category) & 4.24 & 4.07 & 4.33 & 3.86 \\
\hline Bill independently & 0.34 & 0.33 & 0.40 & 0.32 \\
\hline Must accept MDs decision & 0.08 & 0.09 & 0.03 & 0.13 \\
\hline Urban & 0.84 & 0.90 & 0.73 & 0.87 \\
\hline Turnover intention & 0.22 & 0.18 & 0.21 & 0.18 \\
\hline
\end{tabular}

Table 3 presents the estimated coefficients that result from our logistic regression of turnover intentions in the four subsamples. Table 4 presents the standardized coefficients from the same models; these can be useful when trying to discern variables' comparative impacts.

TABLE 3

ESTIMATED COEFFICIENTS FROM THE LOGISTIC REGRESSION OF TURNOVER ${ }^{1}$

\begin{tabular}{|l|c|c|c|c|}
\hline \multicolumn{1}{|c|}{ Variable } & Other & Internal & Primary & Surgical \\
\hline Sample size & 2,032 & 1,345 & 3,843 & 724 \\
\hline Intercept & $-1.38^{* * *}$ & $-1.07^{* *}$ & $-1.55^{* * *}$ & $-0.99^{*}$ \\
\hline Factor1: patient workload & $0.53^{* * *}$ & $0.60^{* * *}$ & $0.62^{* * *}$ & $0.72^{* * *}$ \\
\hline Factor2: professional treatment & $0.46^{* * *}$ & $0.54^{* * *}$ & $0.53^{* * *}$ & $0.88^{* * *}$ \\
\hline Factor3: organizational admin & $0.83^{* * *}$ & $0.71^{* * *}$ & $0.69^{* * *}$ & $0.81^{* * *}$ \\
\hline Factor4: salary and benefits & $0.28^{* * *}$ & $0.33^{* * *}$ & $0.50^{* * *}$ & $0.31^{* *}$ \\
\hline Married & $-0.42^{* * *}$ & $-0.41^{*}$ & $-0.37^{* * *}$ & $-0.48^{*}$ \\
\hline Physician present $>\mathbf{5 0 \%}$ time & $-0.29^{*}$ & $-0.76^{* *}$ & $-0.18^{*}$ & $-0.70^{* *}$ \\
\hline Paid hourly & 0.21 & $0.38^{*}$ & $0.40^{* * *}$ & 0.38 \\
\hline Age (category) & 0.05 & $0.12^{* *}$ & 0.02 & 0.03 \\
\hline Bill independently & -0.22 & -0.31 & 0.10 & $-0.56^{*}$ \\
\hline Must accept MDs decision & 0.02 & $0.70^{* *}$ & $0.47^{*}$ & 0.39 \\
\hline Urban & 0.17 & -0.46 & 0.14 & -.025 \\
\hline Tjur's pseudo- $\mathbf{R}^{2}$ & 0.18 & 0.19 & 0.20 & 0.27 \\
\hline $\begin{array}{l}\text { Tjur's pseudo-R for Factors only } \\
\text { model }\end{array}$ & 0.17 & 0.15 & 0.19 & 0.24 \\
\hline
\end{tabular}

${ }^{* * *} \mathrm{p} \leq .001 ;{ }^{* *} \mathrm{p} \leq .01 ;{ }^{*} \mathrm{p} \leq .05 ;{ }^{1}$ Plan to leave principal position in $<2$ years 
Tables 3 and 4 show that all four dissatisfaction variables are positive and statistically significant in all fours subsamples, indicating that increases in dissatisfaction are associated with increases in turnover intentions, as hypothesized. The dissatisfaction with the organizational administration factor has the largest standardized coefficient in all subsamples except the Surgical subsample, where professional treatment has the largest coefficient.

Comparing the pseudo $\mathrm{R}^{2}$ for the full model to the pseudo $\mathrm{R}^{2}$ for the model with just the four dissatisfaction factors, adding the other control variables only slightly increases the explanatory power of the model; see Table 3 or Table 4.

Nevertheless, some of the other control variables achieve statistical significance, with small effects. Across all four subsamples, being married has a significant and negative, but small, effect on turnover intention. Similarly, in all four subsamples, when NPs work with a physician present more than $50 \%$ of the time they are slightly less likely to leave. Those NPs who are paid hourly are more likely to turnover in all four subsamples, but only significantly so in Internal and in Primary. Similarly, NPs who work in an environment where they are supervised by a physician and must accept the physician's decisions are more likely to turnover in all four subsamples, but only significantly so in Internal and in Primary. Older NPs are more likely to have higher turnover intentions in all four subsamples, but only significantly so in the Internal subsample.

TABLE 4

STANDARDIZED COEFFICIENTS FROM THE LOGISTIC REGRESSION OF TURNOVER ${ }^{1}$

\begin{tabular}{|l|c|c|c|c|}
\hline \multicolumn{1}{|c|}{ Variable } & Other & Internal & Primary & Surgical \\
\hline Sample size & 2,032 & 1,345 & 3,843 & 724 \\
\hline Factor1: patient workload & $0.26^{* * *}$ & $0.29^{* * *}$ & $0.30^{* * *}$ & $0.34^{* * *}$ \\
\hline Factor2: professional treatment & $0.22^{* * *}$ & $0.25^{* * *}$ & $0.23^{* * *}$ & $0.42^{* * *}$ \\
\hline Factor3: organizational admin & $0.39^{* * *}$ & $0.32^{* * *}$ & $0.31^{* * *}$ & $0.35^{* * *}$ \\
\hline Factor4: salary and benefits & $0.15^{* * *}$ & $0.17^{* * *}$ & $0.28^{* * *}$ & $0.16^{* *}$ \\
\hline Married & $-0.11^{* * *}$ & $-0.10^{*}$ & $-0.09^{* * *}$ & $-0.12^{*}$ \\
\hline Physician present $>\mathbf{5 0 \%}$ time & $-0.08^{*}$ & $-0.17^{* *}$ & $-0.05^{*}$ & $-0.15^{* *}$ \\
\hline Paid hourly & 0.05 & $0.08^{*}$ & $0.10^{* * *}$ & 0.09 \\
\hline Age (category) & 0.06 & $0.13^{* *}$ & 0.02 & 0.04 \\
\hline Bill independently & -0.06 & -0.08 & 0.03 & $-0.15^{*}$ \\
\hline Must accept MDs decision & 0.01 & $0.11^{* *}$ & $0.04^{*}$ & 0.07 \\
\hline Urban & 0.03 & -0.08 & 0.03 & -.05 \\
\hline Tjur's pseudo- $\mathbf{R}^{2}$ for full model & 0.18 & 0.19 & 0.20 & 0.27 \\
\hline $\begin{array}{l}\text { Tjur's pseudo-R for Factors only } \\
\text { model }\end{array}$ & 0.17 & 0.15 & 0.19 & 0.24 \\
\hline
\end{tabular}

${ }^{* * *} \mathrm{p}<.001 ;{ }^{* *} \mathrm{p}<.01 ;{ }^{*} \mathrm{p}<.05 ; 1$ Plan to leave principal position in $<2$ years

Fit of the logistic regression models was examined by first ensuring that the global null hypothesis test had a p-value $\leq 0.05$. This was true for the models of factors only on all four subsamples and the full models on all four subsamples. Next, we compared the fit of models, starting with the null model (model with intercept only), progressing to the model with factors only, then, finally, to the full model. As shown in Table 5, both Akaike's information criterion (AIC) and the Schwarz criterion (SC) continued getting smaller, with the smallest value being the full model. Smaller values for both of these measures indicate a better model fit in all four subsamples. Lastly, we compared Tjur's (2009) pseudo $\mathrm{R}^{2}$, see Table 5. A 
larger value of Tjur's indicates a better fitting model (Tjur, 2009). The value of Tjur's increased between the factors only model and the full model in all four subsamples. Each of these tests, for all four subsamples, indicated that our final "full model" was a good fit.

TABLE 5

MODEL FIT RESULTS

\begin{tabular}{|l|l|l|r|r|}
\hline Measure/model & Other & Internal & Surgical & Primary \\
\hline AIC null model & 2158.339 & 1251.360 & 677.491 & 3936.235 \\
\hline SC null model & 2163.956 & 1256.565 & 682.076 & 3942.489 \\
\hline AIC factors only model & 1839.275 & 1076.742 & 534.831 & 3290.464 \\
\hline SC factors only model & 1867.359 & 1102.762 & 557.755 & 3321.734 \\
\hline AIC full model & 1823.900 & 1043.611 & 529.840 & 3259.859 \\
\hline SC full model & 1891.302 & 1106.061 & 584.857 & 3334.907 \\
\hline
\end{tabular}

$\mathrm{AIC}=$ Akaike's information criterion

$\mathrm{SC}=$ Schwarz criterion

\section{DISCUSSION}

Our research finds that the primary determinants of turnover intentions are measures of job dissatisfaction. Comparing the pseudo $\mathrm{R}^{2}$ statistics for the full model to those from the model with only the dissatisfaction factors, adding the control variables increased $\mathrm{R}^{2}$ from $17 \%$ to $18 \%$ in the Other subsample, $15 \%$ to $19 \%$ in the Internal subsample, $19 \%$ to $20 \%$ in the Primary subsample, and $24 \%$ to $27 \%$ in the Surgical subsample. Our analysis of the fit of the models showed that these small increases in fit were statistically significant. Thus, while the addition of the control variables increased the fit of the model by a statistically significant amount, the four job dissatisfaction factors explain far more variance in turnover intentions than all of the control variables taken together. This finding suggests that employers of NPs have the ability to influence turnover intentions and subsequent turnover behavior by focusing on sources of job dissatisfaction.

In particular, dissatisfaction with organizational administration (Factor 3, composed of dissatisfaction with administrative support, professional development, and with input into organizational/practice policies) had the largest standardized effect on turnover intentions of all variables in the model, except for in the Surgical subsample, where Factor 3 still had a similar sized impact as in the other three subsamples, although dissatisfaction with professional treatment (Factor 2, composed of dissatisfaction with the sense of value for what you do, respect from physician colleagues, respect from other colleagues, and the level of autonomy) had an even larger effect. Dissatisfaction with professional treatment (Factor 2) had similarly sized effect in the Other, Internal, and Primary subsamples, but the effect size in the Surgical subsample was almost twice as large as in the remaining subsamples. Dissatisfaction with patient workload (Factor 1, composed of dissatisfaction with the proportion of time in patient care, the patient load, the patient mix, the amount of paperwork required, and the number of hours worked) had a similar effect across all four subsamples. Dissatisfaction with salary and benefits (Factor 4) had the smallest effect in all subsamples except in Primary.

Our findings are similar to those of studies of NPs that are currently available in the literature. Similar to a study of turnover intentions of NPs that found that the relationship between NPs and administration was ranked the lowest of all aspects of NP practice environment (Poghosyan, Liu, Shang, and D'Aunno, 2017), we found that the largest effect on increasing turnover intentions was dissatisfaction with organizational administrative items (dissatisfaction with administrative support, professional development, and with input into organizational/practice policies), except in the Surgical subsample where it still had a similar effect. A study by De Milt, Fitzpatrick, and McNulty (2011) found a significant 
relationship between job satisfaction and anticipated turnover: the lower job satisfaction, the higher the reported turnover intention. One of the job satisfaction items scoring lowest in a study of Certified Registered Nurse Anesthetists (who are one type of NP) was their level of representation in administrative planning and decision making (Penprase, 2014). Another study of NPs had two main findings: (1) autonomy is a key factor associated with professional satisfaction, and (2) NPs were less satisfied with their input into organizational practices and policies than other areas of their practice (Athey et al., 2016).

Variables that are outside of the control of the employer such as marital status, age, and place of residence, while they may affect turnover intentions, have small effects. The other variables that employers have control over - the amount of time a physician is present, if NPs are paid hourly or are salaried, whether NPs are allowed to bill independently, and whether they are supervised by a physician whose decisions they must accept - also have small effects.

Taken together, our results suggest that employers of NPs can reduce turnover intentions, and the subsequent turnover that follows, by ensuring that:

- NPs have appropriate administrative support, opportunities for professional development, and input into organizational policies to reduce dissatisfaction with organizational administration.

- NPs are valued, are respected by physicians and other colleagues, and allowed autonomy to reduce dissatisfaction with professional treatment.

- NPs have appropriate time for patient care, the appropriate patient load and mix, are not overloaded with paperwork, and do not work excessively long hours to reduce dissatisfaction with patient workload.

- NPs receive appropriate pay and benefits to reduce dissatisfaction with compensation.

Similar practice implications are provided in Poghosyan, Liu, Shang, \& D'Aunno (2017: 8), "Health care organizations with practice environments that support autonomous action, clear NP roles, collegial relationships, and NP practice will ultimately promote NP job satisfaction and intentions of staying in their current positions."

Note that some of the changes suggested by our research are self-reinforcing, which helps pay for the changes. For example, our results show that improving organizational administration and professional treatment results in lower turnover of NPs, which reduces short-staffing and overtime, thus allowing (without increasing costs) improvements in patient workload, which our results show further reduces turnover.

The next twenty years will include numerous demographic changes in the United States. Probably the largest will be the continuing retirement of most all of the baby boomer generation, including those working actively today as NPs. In our sample, the average age of the NP workforce was 48 years (U.S. Department of Health and Human Services, 2014b), suggesting that many NPs will also be retiring within that timeframe. An additional demographic factor increasing demand for healthcare will be the increase of elderly in the population; the oldest members of our population require the most care, so the increase of elderly in the population will significantly increase the demand for healthcare. The increased demand for healthcare, coupled with the continual battle to maintain or reduce the level of healthcare costs, suggests that more and more NPs will be used as a less costly alternative to physicians whenever possible. Important to both patients and the healthcare system is that, according to a systematic review by Newhouse et al. (2011: 248), NPs "provide safe, effective, quality care to a number of specific populations in a variety of settings". A study of NP job satisfaction (Pasaron, 2013) found that the greatest level of dissatisfaction reported by NPs was dissatisfaction with professional and monetary recognition, assertive influence, administrative support, and collegial relationships. Therefore, successful implementation of the changes suggested by our research can help healthcare providers lower turnover of NPs and thus position themselves to more effectively manage the coming demographic trends.

Turnover of NPs will interfere with both the access to and the quality of healthcare in the United States. As Poghosyan, Liu, Shang, and D'Aunno (2017: 7) point out, keeping NPs in their clinical positions is "important for maintaining a robust NP workforce in primary care practices that can address the quality and access to care issues facing our primary care system". There are several types of costs 
associated with NP turnover. Employers will initially bear much of the cost, both in indirect costs and direct costs. Direct costs include all recruiting and hiring costs: advertising, interviewing, selecting, background checks, training new employees, etc., plus the staff costs incurred to perform these tasks. Some of the indirect costs include paying overtime to current NPs, having manager NPs work to fill empty NP positions, loss of revenue if there is no one to provide the services that the departed NPs did, and the lower productivity of any newly hired NPs (Jones, 2004; O'Brien-Pallas, 2006). Therefore, successful implementation of the changes suggested by our research can help reduce the costs associated with turnover, and thus improve access to and quality of healthcare.

NP turnover also has numerous social costs and implications. The access to some services will decrease as the NPs leave their positions. Any healthcare provider that has, as a result of losing NPs, ended up with less staff than they require for their patient load will certainly not provide as high a level of patient care as previously when not short of staff. Another implication is that the costs incurred by employers will be passed on to any payers, whether to the patient themselves or to third party payers. This means that government programs such as Medicare will pay higher costs for services provided; this will either result in higher taxes to cover the increased costs, or a decreased quantity of Medicare services being available. Other third-party payers, such as insurance companies, will also have these costs passed on to them and will, in turn, pass costs on to their customers purchasing insurance. Therefore, successful implementation of the changes suggested by our research can reduce turnover and reduce the costs associated with turnover, thus reducing the need for higher taxes or reduced availability of medical services.

Considered together, our results suggest that improving administrative support, opportunities for professional development, and input into organizational policies, ensuring that NPs are valued, are respected by physicians and other colleagues, and are allowed autonomy, ensuring that NPs have appropriate time for patient care, the appropriate patient load and mix, are not overloaded with paperwork, and do not work excessively long hours, and ensuring that NPs receive appropriate pay and benefits, will reduce turnover, which reduces costs, and improves access to and quality of patient care. These reductions in costs and improvements to the access and quality of care matter to NPs, patients, employers, third-party payers, and society at large. NPs benefit from improvements to their work life. Employers benefit by reducing NP turnover in a cost-effective manner. Patients, third-party payers, and society benefit from have improved access to better care while cost increases are reduced.

\section{LIMITATIONS}

This study has limitations. The greatest limitation is that many of the measures from the original survey are either redacted or grouped together in large, homogeneous groups. For example, the categories of practice type of NP are only Primary, Internal, Surgical, and Other in the public use file we currently have, while the original survey included 32 different types of NPs. As another example, age and earnings are turned into categorical measures in the public use file, while the actual values are available in the nonredacted data file. We are in the process of writing a grant to obtain access to the full data so that we can do a more detailed, setting specific analysis of NP turnover. 


\section{REFERENCES}

Adams, A., \& Bond, S. (2000). Hospital nurses' job satisfaction, individual and organizational characteristics. Journal of advanced nursing, 32(3), 536-543.

Agresti, A. (2007). An Introduction to Categorical Data Analysis. Hoboken: John Willey and Sons.

Aiken, L. H., Cimiotti, J. P., Sloane, D. M., Smith, H. L., Flynn, L., \& Neff, D. F. (2011). The effects of nurse staffing and nurse education on patient deaths in hospitals with different nurse work environments. Medical care, 49(12), 1047.

Athey, E. K., Leslie, M. S., Briggs, L. A., Park, J., Falk, N. L., Pericak, A., ... \& Greene, J. (2016). How important are autonomy and work setting to nurse practitioners' job satisfaction?. Journal of the American Association of Nurse Practitioners, 28(6), 320-326.

Bureau of Labor Statistics, U.S. Department of Labor. (2016, May). Occupational Outlook Handbook. Retrieved 7/24/17, from https://www.bls.gov/ooh/healthcare/registered-nurses.htm.

Darcie, G., Fitzpatrick, J. J., \& McNulty, S. R. (2011). Nurse practitioners' job satisfaction and intent to leave current positions, the nursing profession, and the nurse practitioner role as a direct care provider. Journal of the American Academy of Nurse Practitioners, 23(1), 42-50.

Guilford, J. (1954). Psychometric Methods, 2nd ed. New York: McGraw-Hill.

Jones, C. B. (2004). The costs of nurse turnover: part 1: an economic perspective. Journal of Nursing Administration, 34(12), 562-570.

Jones, C. B. (2005). The costs of nurse turnover, part 2: application of the nursing turnover cost calculation methodology. Journal of Nursing Administration, 35(1), 41-49.

Kurnat-Thoma, E., Ganger, M., Peterson, K., \& Channell, L. (2017). Reducing annual hospital and registered nurse staff turnover - a 10-element onboarding program intervention. SAGE Open Nursing, 3, 2377960817697712.

Kutner M., Nachtsheim C., \& Neter J. (2004). Applied linear regression models. McGraw-Hill/Irwin.

Locke, E. A. (1969). What is job satisfaction? Organizational behavior and human performance, 4(4), 309-336.

Lord, F., and Novick, R. (1974). Statistical Theories of Mental Test Scores. Reading, Mass.: AddisonWesley.

Midi, H., Sarkar, S. K., \& Rana, S. (2010). Collinearity diagnostics of binary logistic regression model. Journal of Interdisciplinary Mathematics, 13(3), 253-267.

Mobley, W. H., Horner, S. O., \& Hollingsworth, A. T. (1978). An evaluation of precursors of hospital employee turnover. Journal of Applied psychology, 63(4), 408-414.

Nantsupawat, A., Srisuphan, W., Kunaviktikul, W., Wichaikhum, O. A., Aungsuroch, Y., \& Aiken, L. H. (2011). Impact of nurse work environment and staffing on hospital nurse and quality of care in Thailand. Journal of Nursing Scholarship, 43(4), 426-432.

Newhouse, R. P., Stanik-Hutt, J., White, K. M., Johantgen, M., Bass, E. B., Zangaro, G., ... \& Weiner, J. P. (2011). Advanced practice nurse outcomes 1990-2008: a systematic review. Nursing Economics, 29(5), 230.

Nunnally, J. C. (1978). Psychometric theory (2nd ed.). New York: McGraw-Hill.

O’Brien-Pallas, L., Griffin, P., Shamian, J., Buchan, J., Duffield, C., Hughes, F., ... \& Stone, P. W. (2006). The impact of nurse turnover on patient, nurse, and system outcomes: a pilot study and focus for a multicenter international study. Policy, Politics, \& Nursing Practice, 7(3), 169-179.

Pasarón, R. (2013). Nurse practitioner job satisfaction: looking for successful outcomes. Journal of Clinical Nursing, 22(17-18), 2593-2604.

Penprase B. (2014). Job satisfaction among certified registered nurse anesthetists: a multigenerational analysis. Anesthesia eJournal, 2(1).

Poghosyan, L., Liu, J., Shang, J., \& D'aunno, T. (2017). Practice environments and job satisfaction and turnover intentions of nurse practitioners: Implications for primary care workforce capacity. Health care management review, 42(2), 162-171.

SAS Software, Version 9.4 of the SAS System for Windows. (2017). Cary, NC: SAS Institute Inc. 
Tett, R. P., \& Meyer, J. P. (1993). Job satisfaction, organizational commitment, turnover intention, and turnover: path analyses based on meta-analytic findings. Personnel psychology, 46(2), 259-293.

Tjur, T. (2009). Coefficients of determination in logistic regression models-A new proposal: The coefficient of discrimination. The American Statistician, 63(4), 366-372.

U.S. Department of Health and Human Services, Health Resources and Services Administration, National Center for Health Workforce Analysis (2014a). The 2012 National Sample Survey of Nurse Practitioners [Data set]. Rockville, Maryland; 2014.

U.S. Department of Health and Human Services, Health Resources and Services Administration, National Center for Health Workforce Analysis (2014b). Highlights From the 2012 National Sample Survey of Nurse Practitioners. Rockville, Maryland: U.S. Department of Health and Human Services, 2014. 